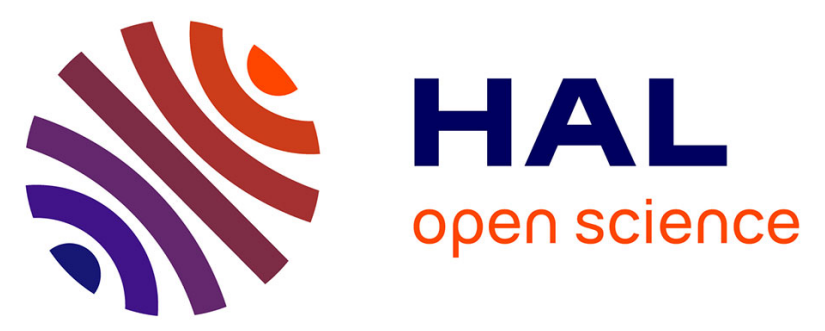

\title{
Non-pegylated liposomal doxorubicin combined with gemcitabine as first-line treatment for metastatic or locally advanced breast cancer. Final results of a phase I/II trial
}

S. Barco, R. Colomer, L. Calvo, I. Tusquets, E. Adrover, P. Sánchez, J. Rifà, J. Haba, J. A. Virizuela

\section{To cite this version:}

S. Barco, R. Colomer, L. Calvo, I. Tusquets, E. Adrover, et al.. Non-pegylated liposomal doxorubicin combined with gemcitabine as first-line treatment for metastatic or locally advanced breast cancer. Final results of a phase I/II trial. Breast Cancer Research and Treatment, 2008, 116 (2), pp.351-358. 10.1007/s10549-008-0218-8 . hal-00478274

\section{HAL Id: hal-00478274 https://hal.science/hal-00478274}

Submitted on 30 Apr 2010

HAL is a multi-disciplinary open access archive for the deposit and dissemination of scientific research documents, whether they are published or not. The documents may come from teaching and research institutions in France or abroad, or from public or private research centers.
L'archive ouverte pluridisciplinaire HAL, est destinée au dépôt et à la diffusion de documents scientifiques de niveau recherche, publiés ou non, émanant des établissements d'enseignement et de recherche français ou étrangers, des laboratoires publics ou privés. 


\title{
Non-pegylated liposomal doxorubicin combined with gemcitabine as first-line treatment for metastatic or locally advanced breast cancer. Final results of a phase I/II trial
}

\author{
S. Del Barco $\cdot$ R. Colomer $\cdot$ L. Calvo $\cdot$ I. Tusquets $\cdot$ \\ E. Adrover $\cdot$ P. Sánchez $\cdot$ J. Rifà $\cdot$ J. De la Haba $\cdot$ \\ J. A. Virizuela
}

Received: 1 October 2008/Accepted: 1 October 2008/Published online: 22 October 2008

(C) Springer Science+Business Media, LLC. 2008

\begin{abstract}
Doxorubicin and gemcitabine are active as single agents in breast cancer, have different mechanisms of action, and mainly have non-overlapping side effects. Dosedependent doxorubicin-related cardiac toxicity is the principal limitation in the metastatic setting. This open, multicenter, single-arm phase I/II study assessed the safety and activity of gemcitabine in combination with non-pegylated liposomal doxorubicin (Myocet $\left.{ }^{\circledR}\right)$, a more cardiacfriendly anthracycline, in the first-line treatment of patients with advanced breast cancer. We aimed to determine the optimal recommended dose (RD) of gemcitabine combined
\end{abstract}

\author{
S. Del Barco $(\square)$ \\ Institut Català d'Oncologia (ICO), Hospital Universitario Josep \\ Trueta, Girona, Spain \\ e-mail: sdelbarco@ico.scs.es \\ R. Colomer \\ MD Anderson, Madrid, Spain \\ L. Calvo \\ Hospital Juan Canalejo, La Coruna, Spain \\ I. Tusquets \\ Hospital del Mar, Barcelona, Spain \\ E. Adrover \\ Hospital General Universitario, Alicante, Spain \\ P. Sánchez \\ Complejo Hospitalario ciudad de Jaén, Jaen, Spain \\ J. Rifà \\ Hospital Son Dureta, Palma de Mallorca, Spain \\ J. De la Haba \\ Hospital Universitario Reina Sofía, Cordoba, Spain \\ J. A. Virizuela \\ Hospital Virgen Macarena, Sevilla, Spain
}

with Myocet ${ }^{\circledR}$ in a population, with performance status $\geq 2$ and LVEF $\geq 50 \%$. A formal phase II study was performed afterwards. A total of 53 patients were recruited. Gemcitabine $900 \mathrm{mg} / \mathrm{m}^{2}$ intravenously day 1 and 8 combined with Myocet ${ }^{\circledR} 55 \mathrm{mg} / \mathrm{m}^{2}$ intravenously day 1 , every 21 days, was the final RD. The principal toxicity observed was hematological, and $48 \%$ of patients developed grade 3-4 neutropenia. Other toxicities were mild and infrequent, including nausea and vomiting. There were no symptomatic cardiac events despite the fact that $36 \%$ of the patients had received prior treatment with adjuvant anthracyclines. Objective responses were observed in $51.1 \%$ of 47 evaluable patients (95\% CI: 36-66\%), including two complete response. In addition, 14 patients $(29.8 \%)$ demonstrated stable disease. The combination of Myocet ${ }^{\circledR}$ and gemcitabine at the RD is safe and has encouraging clinical activity in patients with advanced breast cancer, without apparent cardiac toxicity in anthracycline-pretreated patients. These data support further development of this combination.

Keywords Liposomal doxorubicin - Gemcitabine . Advanced breast cancer

\section{Introduction}

In 2007, the incidence of this disease reached 180,510 new cases in the USA and 40,910 deaths were attributed to this type of tumor [1]. There have been major advances in the management of breast cancer which have resulted in less aggressive surgery and better overall survival [2-4]. However, there has been less progress in patients who present or develop metastatic disease.

The anthracyclines have been one of the cornerstones in the breast cancer treatment. In the adjuvant setting, there is 
evidence of improved time to progression and overall survival in patients treated with regimens involving doxorubicin [5-8]. In patients with metastatic disease, doxorubicin has resulted in response rates of $30-50 \%$. The drug, however, induces a cumulative dose-dependant cardiac toxicity characterized by a progressive myopathy that can lead to fatal congestive heart failure (CHF) $[9,10]$. Importantly, the risk of CHF has been found to increase at cumulative doses over $450 \mathrm{mg} / \mathrm{m}^{2}$ [11]. This finding is of special interest because of the increasing use of doxorubicin in the adjuvant setting, which could lead to limitation of its use in the metastatic disease. One strategy to reduce this problem has been the use of liposomal technology $[12,13]$.

Non-pegylated liposomal doxorubicin (NPLD) $\left(\right.$ Myocet $^{\circledR}$ ) is a complex of doxorubicin citrate encapsulated in nonpegylated liposomes. Myocet ${ }^{\circledR}$ was developed to selectively reduce the release of active doxorubicin in normal tissues while increasing its concentration in tumor tissues, with the aim of reducing toxicity and increasing efficacy [12, 14-16]. Because of their size, the liposomes do not pass through the capillary beds of normal tissues while they readily diffuse through the chaotic and highly permeable capillaries of tumors. A series of phase II and III studies have shown that NPLD, both as single agent or in combination with other drugs, is effective and safe in patients with breast cancer with an associated reduction in incidence and severity of cardiac events $[15,17-20]$.

One of the newest drugs with activity in breast cancer is gemcitabine. Administered as a single agent to patients with advanced breast cancer, gemcitabine is very well tolerated and results in a 15-46\% response rate [21-23]. Gemcitabine has been tested in combination with doxorubicin in a phase II study conducted in Spain [24]. In this trial, gemcitabine was administered at doses of $800-1,000 \mathrm{mg} / \mathrm{m}^{2}$ and doxorubicin was given at $25 \mathrm{mg} / \mathrm{m}^{2}$ on a 3-out-of-every-4-weeks basis. However, most patients required either dose reduction or omission of treatment on day 15 due to hematological toxicities. The overall response rate was $55 \%$. The median time to progression was 11.5 months and the overall survival was 27 months. Although only one patient had an asymptomatic decrease in the left ventricular ejection fraction (LVEF), it should be taken into account that only $19 \%$ of patients had received previous anthracyclines. Based on these data, the combination of gemcitabine and doxorubicin appears attractive in patients with breast cancer.

Considering the different mechanisms of action and non-overlapping toxicity profiles of NPLD and gemcitabine as single agents, and the activity observed with the combination of conventional doxorubicin and gemcitabine, we designed this open, multicenter, single-arm phase I/II study to test the efficacy and safety of the NPLD (Myocet ${ }^{\circledR}$ ) and gemcitabine combination in the first line treatment of patients with advanced or locally advanced breast cancer.

\section{Patients and methods}

\section{Patients}

Patients with histologically confirmed metastatic or locally advanced breast cancer, with at least one measurable lesion according to the RECIST criteria [25], were enrolled in this study between February 2003 and September 2005 in eight Spanish centers. Other eligibility criteria included age over 18 years; ECOG (Eastern Cooperative Oncology Group) performance status of $\leq 2$; life expectancy of $>3$ months; hemoglobin $\geq 10 \mathrm{~g} / \mathrm{dl}$, neutrophils $\geq 2,000 / \mu$, platelets $\geq 100,000 / \mu \mathrm{l}$, and adequate liver, renal and cardiac (left ventricular ejection fraction (LVEF) $\geq 50 \%$ ) functions. Patients who had received adjuvant therapy were required to have had a disease-free interval of at least 12 months after completion of therapy, and for those who had received prior adjuvant anthracycline-based treatment, the total cumulative dose had to be $<300 \mathrm{mg} / \mathrm{m}^{2}$ for doxorubicin and $450 \mathrm{mg} / \mathrm{m}^{2}$ for epirubicin; previous hormonal treatment and radiotherapy (provided it had not affected more than $30 \%$ of the bone marrow reserve) were permitted.

Patients were excluded if they had received previous chemotherapy treatment for advanced disease or were pregnant; patients with severe comorbid conditions or a history of further malignancy, other than basal or squamous cell carcinomas of the skin, carcinoma in situ of the cervix, or contralateral breast cancer, in the last 5 years were not eligible. No other restrictions due to age or extent of disease were used. All patients signed an informed consent form before the study entry. The study protocol was approved by the institutional review board of each participating institution and the studies were conducted in accordance with the principles of the Declaration of Helsinki and the applicable guidelines for Good Clinical Practice.

\section{Drugs administration}

In the dose escalation part of the study, patients were treated in cohorts with escalating doses of gemcitabine. All patients received a fixed dose of NPLD $\left(60 \mathrm{mg} / \mathrm{m}^{2}, 1 \mathrm{~h}\right.$ infusion $)$ administered on day 1 . The starting dose of gemcitabine was $1,000 \mathrm{mg} / \mathrm{m}^{2}$, administered i.v. for $30 \mathrm{~min}$ on days 1 and 8 , every 21 days. The dose of gemcitabine was scheduled to be escalated up to $1,200 \mathrm{mg} / \mathrm{m}^{2}$ in the subsequent cohort. The maximum total number of cycles was 6 . The RD was defined as the highest dose at which less than one-third of patients developed DLT during the first two courses. 
Toxicity was graded according to the National Cancer Institute Common Toxicity Criteria, version 2 . Intrapatient dose escalation was not permitted. DLT was defined as the following: (a) delay in treatment of more than 7 days due to hematological toxicity; (b) febrile neutropenia; (c) thrombocytopenia with bleeding of grade $\geq 3$, and (d) nonhematological toxicity of grade $\geq 3$, except for nausea and/ or vomiting in the absence of an appropriate anti-emetic regimen.

Patients received anti-emetic treatment at the physician's discretion. The use of prophylactic colony-stimulation factors was not allowed.

\section{Study design}

This was an open, multicenter, single-arm phase I/II study. Pretreatment examination included a complete medical history and physical examination with ECOG performance status, complete blood cell (CBC) count, standard biochemistry including the tumor marker CA 15.3 , electrocardiogram and an analysis of the LVEF, and clinical tumor assessment (if possible, computed tomography (CT) scans of the chest and abdomen, and bone scan). Physical examination, monitoring of toxic effects, and a $\mathrm{CBC}$ were performed at the beginning of each cycle. A CBC was also obtained on day 8 before the administration of gemcitabine. Response was evaluated after every three cycles of chemotherapy and every 3 months thereafter. An electrocardiogram was performed before each course. LVEF analysis was repeated at least at off-study.

Before the start of a cycle, an ANC of $>1,500 / \mu \mathrm{l}$ and platelets $>100,000 / \mu \mathrm{l}$ were required. The presence of anemia did not required dose modification. All non-hemato logical toxicities were required to return to grade 1 , excluding alopecia and/or vomiting, before treatment. Adjustments of dose were based on the nadir hematological values for the preceding cycle. Dose reductions were maintained for all subsequent cycles. Treatment was delayed for a maximum of 3 weeks to allow recovery.

\section{Study endpoints}

The primary endpoint of the phase I study was to determine the RD of the combination of non-pegylated liposomal doxorubicin and gemcitabine as first-line treatment of patients with metastatic or locally advanced breast cancer. The primary objective of the phase II study was to determine the overall response rate (ORR) to the combination, which was defined as complete response and partial response in patients treated with the RD.

Secondary aims included determining time to progression, time to response, response duration, time to treatment failure, 1-year survival, overall survival, and safety.
Statistical analysis

All patients were assessable for response and toxicity according to the intention-to-treat principle. Progressionfree survival was measured from the date of initial treatment to the date of disease progression. Overall survival was measured from the date of the first course of chemotherapy to the date of death or to the last follow-up examination. Time-to-event distributions were estimated by Kaplan-Meier analysis [26]. 95\% Confidence intervals for response rate were calculated using methods for exact binomial confidence interval estimation [27]. Qualitative factors were compared using Pearson $\chi^{2}$ contingency table analysis.

A sample size of 48 patients in the phase II study was planned on the basis of $80 \%$ power to demonstrate a $55 \%$ response rate, assuming a lower level of interest of $30 \%$ with a one-sided test of 0.05 .

All endpoints were also analyzed in the subgroup of patients that had received previous anthracycline treatment, and compared using the log-rank method. The SAS statistics program, version 8.2, was used for all statistical analyses.

\section{Results}

\section{Patient characteristics}

A total of 53 patients with metastatic or locally advanced breast cancer were included in the study. Of those patients, 20 received NPLD $60 \mathrm{mg} / \mathrm{m}^{2}$ and gemcitabine $1,000 \mathrm{mg} / \mathrm{m}^{2}$ or dose level 1 (DL-1) (60/1,000 regimen) and 33 received NPLD $55 \mathrm{mg} / \mathrm{m}^{2}$ and gemcitabine $900 \mathrm{mg} / \mathrm{m}^{2}$ or dose level 2 (DL-2) (55/900 regimen) (see below). All 53 patients were included in the safety population. However, six of these patients withdrew from the study without any postbasal tumor assessment. One patient withdrew because of a protocol deviation, one patient withdrew consent, one patient due to an adverse event (hidroneumothorax), two patients due to grade 4 treatment-related toxicity (the first one developed grade 4 emesis and the second one developed grade 4 diarrhea, grade 4 febrile neutropenia, and grade 4 plaquetopenia) and one because of rapid progression with CNS metastasis and exitus. Thus, the efficacy population only included 47 patients. Patient characteristics of the efficacy population are summarized in Table 1 . Median age was 59 years (range 32-79) and 29\% of the patients had hormone receptor positive cancers; the majority of tumors were ductal infiltrating carcinoma (92\%) and $37 \%$ of patients had visceral (lung or liver) metastatic disease. 
Table 1 Baseline patient characteristics

\begin{tabular}{|c|c|c|c|}
\hline Characteristics & DL-1 $(n=19)$ & DL-2 $(n=28)$ & Total $(n=47)$ \\
\hline Age in years, mean (range) & $58(42-73)$ & $61(32-79)$ & $60(32-79)$ \\
\hline Postmenopausal, $N(\%)$ & $17(90)$ & $23(82)$ & $40(85)$ \\
\hline \multicolumn{4}{|c|}{ Functional stage performance status (ECOG) } \\
\hline 0 & $10(53)$ & $18(64)$ & $28(60)$ \\
\hline 1 & $8(42)$ & $9(32)$ & $17(36)$ \\
\hline 2 & $1(5)$ & $1(4)$ & $2(4)$ \\
\hline Prior cardiovascular events, $N(\%)$ & $4(21)$ & $9(32)$ & $13(28)$ \\
\hline Controlled hypertension & 3 & 8 & 11 \\
\hline Peripheral arteriopathy & 1 & 0 & 1 \\
\hline Prior CVA & 0 & 1 & 1 \\
\hline $\mathrm{LVEF} \geq 50 \%$ & $19(100)$ & $28(100)$ & $47(100)$ \\
\hline \multicolumn{4}{|l|}{ Tumor histology, $N(\%)$} \\
\hline Ductal & $17(90)$ & $26(93)$ & $43(92)$ \\
\hline Lobular & 0 & $2(7)$ & $2(4)$ \\
\hline \multicolumn{4}{|l|}{ Tumor stage, $N(\%)$} \\
\hline I & $3(16)$ & $1(4)$ & $4(9)$ \\
\hline II & $7(37)$ & $7(25)$ & $14(30)$ \\
\hline III & $3(16)$ & $6(21)$ & $4(9)$ \\
\hline \multicolumn{4}{|l|}{ Hormone receptors, $N(\%)$} \\
\hline Positive & $14(74)$ & $15(54)$ & $29(62)$ \\
\hline Negative & $4(21)$ & $9(32)$ & $13(28)$ \\
\hline Unknown & $1(5)$ & $4(14)$ & $5(10)$ \\
\hline \multicolumn{4}{|l|}{ Serum HER2 determination, $N(\%)$} \\
\hline Positive & $2(10)$ & $2(7)$ & $4(8)$ \\
\hline Negative & $15(79)$ & $23(82)$ & $38(81)$ \\
\hline Unknown & $2(10)$ & $3(11)$ & $5(11)$ \\
\hline \multicolumn{4}{|l|}{ Previous treatments, $N(\%)$} \\
\hline Surgery & $17(89)$ & $18(64)$ & $35(74)$ \\
\hline Radiotherapy & $15(79)$ & $12(43)$ & $27(57)$ \\
\hline Adjuvant chemotherapy & $14(74)$ & $12(43)$ & $26(55)$ \\
\hline Adjuvant hormonotherapy & $12(63)$ & $12(43)$ & $24(51)$ \\
\hline \multicolumn{4}{|l|}{ Previous chemotherapy, $N(\%)$} \\
\hline No & $5(26)$ & $16(57)$ & $21(45)$ \\
\hline Anthracyclines & $12(63)$ & $5(18)$ & $17(36)$ \\
\hline \multicolumn{4}{|l|}{ Metastatic sites, $N(\%)$} \\
\hline Lymph nodes & $9(47)$ & $14(50)$ & $23(49)$ \\
\hline Liver & $8(42)$ & $13(46)$ & $21(45)$ \\
\hline Lung & $9(47)$ & $7(25)$ & $16(34)$ \\
\hline Bone & $3(16)$ & $7(25)$ & $10(21)$ \\
\hline Soft tissue & $3(16)$ & $3(11)$ & $6(13)$ \\
\hline Others & 0 & $2(7)$ & $2(4)$ \\
\hline
\end{tabular}

DLTs were observed in these patients, the dose of gemcitabine on day 8 had to be reduced (between 25 and $50 \%$ of the dose) in four of the 14 cycles administered (28.5\% of the cycles) due to neutropenia. Moreover, in three out of the seven patients the administration of cycle 2 was delayed between 4 and 7 days due to neutropenia on day 1 of cycle 2 . For safety and feasibility reasons, 60/1,000 was considered 
the RD for the phase II part, without a subsequent further increase in dose to the next level.

Phase II: efficacy and toxicity

During the phase II study, thirteen more patients received the $60 / 1,000$ regimen, so a total of 20 patients were treated with the RD. A total of 14 severe adverse events were registered for nine patients. Most of the adverse events were hematological toxicity, including seven cases of febrile neutropenia (10\% of the cycles) and five cases of grades 3 and 4 thrombocytopenia ( $7 \%$ of the cycles). Given that the dose of the combination (liposomal doxorubicin $60 \mathrm{mg} / \mathrm{m}^{2}$ and gemcitabine $1,000 \mathrm{mg} / \mathrm{m}^{2}$ ) was jeopardizing the safety or intensity of the total dose received, a $10 \%$ reduction in the dose of both drugs was subsequently used for the new patients enrolled in the study $(n=33)(55 / 900$ regimen).

A total of 235 cycles (101 in DL-1 and 134 in DL-2) were administered, with a median of five cycles per patient (range 2-6). Delay in treatment administration was reported in 61 cycles (30 in DL-1 and 31 in DL-2). The most common reason for delay was hematological toxicity (40 cycles, 17\%). Dose reduction related to hematological toxicity was done in 81 cycles (34\%) (Table 2). Mean dose intensity administered was $52.33 \mathrm{mg} / \mathrm{m}^{2}$ for liposomal doxorubicin and $1,524.71 \mathrm{mg} / \mathrm{m}^{2}$ for gemcitabine. The relative dose intensity was $91.94 \%$ for gemcitabine and $81.26 \%$ for liposomal doxorubicin.

In the total population, $35.8 \%$ of patients experienced some treatment-related adverse events (10 patients in DL-1 and 9 in DL-2). Grade 3 and 4 hematological and nonhematological toxicities are summarized in Table 3. It is noteworthy that a total of five patients (one in DL- 1 and four in DL-2) withdrew from the study due to treatmentrelated toxicity: in the DL-1 group, one patient developed pneumotoxicity related to gemcitabine treatment after cycle 5 . This patient required symptomatic treatment and continued monotherapy treatment with NPLD. In the DL-2 group, one patient developed mielotoxicity, one patient developed grade 4 emesis, another patient developed grade 4 diarrhea and febrile neutropenia after dose 8 of the first cycle, and another developed grade 4 neutropenia.

A total of 17 patients (36.1\%) had received prior adjuvant treatment with anthracyclines [10 patients had received
Table 2 Characteristics of treatment administration (efficacy population, $n=47$ )

Table 3 Grade 3 and 4 hematological and nonhematological toxicity according to NCI criteria (safety population, $n=53$ )

\begin{tabular}{llll}
\hline & $\begin{array}{l}\text { DL-1 } \\
(101 \text { cycles })\end{array}$ & $\begin{array}{l}\text { DL-2 } \\
(134 \text { cycles })\end{array}$ & $\begin{array}{l}\text { Total } \\
(235 \text { cycles })\end{array}$ \\
\hline $\begin{array}{l}\text { Delay in cycle administration, } N(\%) \\
\text { Delay due to hematological toxicity, } N(\%)\end{array}$ & $30(30)$ & $31(23)$ & $61(26)$ \\
$\begin{array}{l}\text { Dose reduction, } N(\%) \\
\quad \text { The whole cycle }\end{array}$ & $19(21)$ & $19(14)$ & $40(17)$ \\
$\quad$ Day 8 & $39(39)$ & $14(10)$ & $33(17)$ \\
$\begin{array}{l}\text { Dose reduction due to hematological } \\
\text { toxicity, } N(\%)\end{array}$ & $44(43)$ & $37(10)$ & $72(36)$ \\
\end{tabular}

\begin{tabular}{|c|c|c|c|c|c|}
\hline & \multicolumn{2}{|c|}{ DL-1 $(n=20)$} & \multicolumn{2}{|c|}{ DL-2 $(n=33)$} & \multirow[t]{2}{*}{$P$-value } \\
\hline & Grade 3 & Grade 4 & Grade 3 & Grade 4 & \\
\hline Leukopenia, $n(\%)$ & $8(40)$ & $7(35)$ & $10(30)$ & $6(18)$ & 0.0576 \\
\hline Neutropenia, $n(\%)$ & 0 & $11(55)$ & $8(24)$ & $8(24)$ & 0.0608 \\
\hline Thrombocytopenia, $n(\%)$ & $7(35)$ & $2(10)$ & $4(12)$ & $1(3)$ & 0.0169 \\
\hline Anemia, $n(\%)$ & $3(15)$ & 0 & $6(18)$ & 0 & 1 \\
\hline Febrile neutropenia, $n(\%)$ & $4(20)$ & $2(10)$ & $2(6)$ & $1(3)$ & 0.0896 \\
\hline \multicolumn{6}{|l|}{ Non-hematological toxicity } \\
\hline Nausea, $n(\%)$ & $2(10)$ & 0 & $1(3)$ & $1(3)$ & 0.62 \\
\hline Vomiting, $n(\%)$ & $3(15)$ & 0 & $1(3)$ & $1(3)$ & 0.35 \\
\hline Stomatitis, $n(\%)$ & $5(25)$ & 0 & $4(12)$ & 0 & 0.27 \\
\hline Asthenia, $n(\%)$ & $2(10)$ & 0 & $3(9)$ & $1(3)$ & 1 \\
\hline $\begin{array}{l}\text { Liver enzymes: } \uparrow \text { ALT and/or } \\
\text { AST and/or GGT, } n(\%)\end{array}$ & $1(5)$ & 0 & $7(21)$ & 0 & 0.52 \\
\hline Alopecia, $n(\%)$ & $5(25)$ & 0 & $1(3)$ & $1(3)$ & 0.08 \\
\hline Diarrhea, $n(\%)$ & 0 & $0(0)$ & $1(3)$ & $1(3)$ & 0.52 \\
\hline Anorexia, $n(\%)$ & 0 & 0 & $1(3)$ & 0 & 1 \\
\hline
\end{tabular}


Table 4 Overall response rate and the best response rate (efficacy population and DL-2 population)

\begin{tabular}{llclcc}
\hline & \multicolumn{2}{c}{ Efficacy population $(n=47)$} & \multicolumn{2}{c}{ DL-2 population $(n=30)$} \\
\hline Best response rate & CR & 2 & $(4.3 \%)$ & 0 & $(0.0 \%)$ \\
& PR & 22 & $(46.8 \%)$ & 13 & $(43.3 \%)$ \\
& SD & 14 & $(29.8 \%)$ & 12 & $(40.0 \%)$ \\
& PD & 9 & $(19.1 \%)$ & 5 & $(16.7 \%)$ \\
\hline
\end{tabular}

epirubicin (median dose $419.65 \mathrm{mg} / \mathrm{m}^{2}$, range $282-540$ $\mathrm{mg} / \mathrm{m}^{2}$ ) and seven patients had received doxorubicin (median $282.33 \mathrm{mg} / \mathrm{m}^{2}$, range $200-300 \mathrm{mg} / \mathrm{m}^{2}$ )]. All patients presented a normal LEVF baseline value $(\geq 50 \%)$ according to the protocol inclusion criteria. A total of four patients $(8.5 \%$ ) (3 in DL-1 and 1 in DL-2) had an asymptomatic decrease in the LVEF at the end of the study (range $44.5-49 \%)$. Of these, three had received prior adjuvant treatment with epirubicin.

Forty-seven patients were evaluable for response $(n=47)$. Two of them $(4.3 \%)$ had a complete response (CR) and 22 patients $(46.8 \%)$ had a partial response (PR), thus the overall response rate was $51.1 \%(n=24,95 \% \mathrm{CI}$ : $36-66 \%)$. A total of 14 patients $(29.8 \%)$ had stable disease and nine patients $(19 \%)$ progressed. The overall response rate and the best response rate of the efficacy population are summarized in Table 4. Median time to response was 2.53 months (95\% CI: 2.07-3.72). No statistical differences in overall response rate were observed between those patients who had received adjuvant anthracycline treatment and those who had not $(64.7 \%$ vs. $43.3 \%, P=0.16)$. According to the intention-to-treat analysis, the overall response rate was $45.3 \%$.

After a median follow-up of 19.64 months (range 3-45.5 months), the median time to progression was 12 months (95\% CI: 7.8-19.6 months). Median time to treatment failure was 8.3 months (95\% CI: 3.2-13.8 months). Median response duration was 11.9 months (95\% CI: 5.925.3 ) and median overall survival was 25.4 months (95\% CI: 16.8-31.18 months) (Fig. 1). It is noteworthy that the median time to progression was 15.4 months (95\% CI: 5.325.5 months), of those 14 patients who had stable disease as the best response. Eight of them had progressed and six had stable disease at the last follow-up visit.

\section{Discussion}

This phase I/II clinical trial was performed to determine the $\mathrm{RD}$ of gemcitabine administered on days 1 and 8 every 21 days in combination with Myoce ${ }^{\circledR}$ administered on day 1 , to patients with advanced breast cancer. Although the RD was established in the 60/1,000 regimen, a protocol amendment was approved to reduce the dose of both agents by $10 \%$ for feasibility and safety reasons. The study shows that at a dose of $900 \mathrm{mg} / \mathrm{m}^{2}$ gemcitabine and $55 \mathrm{mg} / \mathrm{m}^{2}$ Myocet ${ }^{\circledR}$, the combination is well tolerated and has encouraging clinical activity in this group of patients.

As expected, the principal toxicity observed was hematological. The frequency and severity of hematological events precluded the conduction of the study according to the initial protocol and required protocol amendments, to permit the assessment of doses that were lower than initially planned. Overall, approximately $50 \%$ of the patients developed grade 3,4 neutropenia. Other toxicities were mild and rare, including a low incidence of nausea and vomiting, which are common in doxorubicin-containing regimens. Importantly, there were no symptomatic cardiac events despite the fact that $36 \%$ of the patients had received prior treatment with anthracyclines. This is particularly important because those patients who have progressed after previous anthracycline-based therapy, and still have potentially sensitive disease, should not be treated with standard doxorubicin due to the potential of cardiac failure-but they could receive NPLD. This was also observed in a retrospective analysis by Batist et al. [15]. In that study, thirty-nine patients who had previously received adjuvant doxorubicin were treated with NPLD 75 or conventional doxorubicin 75 for their metastatic disease. Cardiac events occurred in $22 \%$ of NPLD-treated patients [one congestive heart failure (CHF)] as opposed to in $39 \%$ of conventional doxorubicin-treated patients (three $\mathrm{CHFs}$ ) (log-rank, $P=0.001$ ).

The results of our study must be analyzed in the context of other similar studies. Rivera et al. [28] conducted a phase II clinical trial to determine the clinical efficacy and safety of pegylated liposomal doxorubicin in combination with gemcitabine in patients with metastatic breast cancer. Patients were eligible if they had measurable disease and had had no prior chemotherapy for metastatic disease, and they received pegylated liposomal doxorubicin $24 \mathrm{mg} / \mathrm{m}^{2}$ intravenously on day 1 plus gemcitabine $800 \mathrm{mg} / \mathrm{m}^{2}$ intravenously on days 1 and 8 of each 21-day cycle. Of 49 patients enrolled, 27 had received prior adjuvant chemotherapy (19 with an anthracycline). The previous median cumulative anthracycline dose was $240 \mathrm{mg} / \mathrm{m}^{2}$. Three complete responses and 21 partial responses were achieved in 46 assessable patients, for an overall response rate of 52\% (95\% CI: 37-67\%). Responses were observed in 11 (58\%) of 19 patients with previous anthracycline exposure. 
Fig 1 Overall survival (a), time to progression (b), and progression-free survival (c)
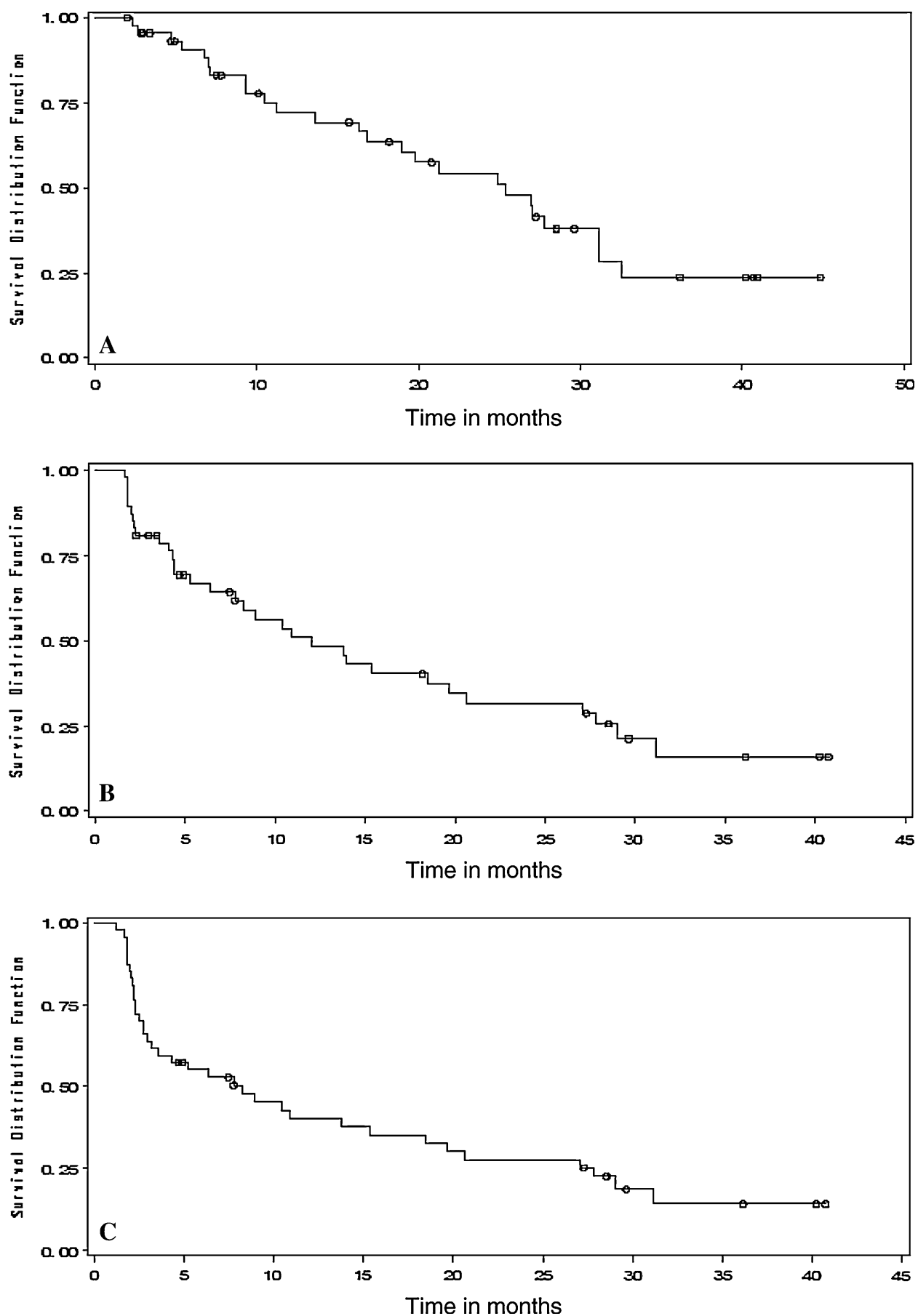

Although these results are very similar to those observed in our study, the median time to progression of 12 months observed with our combination appears to compare very favorably with the 5.6 months obtained with PLD and gemcitabine.

Likewise, Fabi et al. [29] reported a $47.8 \%$ response rate and a median time to progression of 7 months with the same combination of PLD and gemcitabine. Once again, the median time to progression appears to have been lower than that observed in our study. Response rates were similar in patients with and without prior anthracycline treatment. No neutropenic complications were observed, but one patient had a $26 \%$ reduction in LVEF. Other studies have tested gemcitabine in combination with conventional anthracyclines. These studies, including both epirubicin and doxorubicin, showed similar response rates but higher hematological toxicities than the results reported here $[24,30]$. The outcomes of the present study, with a $51 \%$ response rate and a time to progression of 12 months, compare very satisfactorily with the results of these other 
studies, although this might be due, at least in part, to the intrinsic biases of non-comparative phase II trials. In addition, this combination was well tolerated at the recommended phase II dose.

In conclusion, the results of this study show that the combination of Myocet $^{\circledR}$ at a dose of $55 \mathrm{mg} / \mathrm{m}^{2}$ and gemcitabine at a dose of $900 \mathrm{mg} / \mathrm{m}^{2}$ is safe and effective in patients with advanced breast cancer. The reduced dose resulted in less thrombocytopenia and manageable neutropenia. The efficacy data support further investigation of this combination in a phase III clinical trial.

\section{References}

1. Jemal A, Siegel R, Ward E et al (2007) Cancer statistics, 2007. CA Cancer J Clin 57:43-66

2. Cinieri S, Orlando L, Fedele P et al (2007) Adjuvant strategies in breast cancer: new prospectives, questions and reflections at the end of 2007 St Gallen International Expert Consensus Conference. Ann Oncol 18(6):63-65. doi:10.1093/annonc/mdm227

3. Cuzick J (2001) A brief review of the International Breast Cancer Intervention Study (IBIS), the other current breast cancer prevention trials, and proposals for future trials. Ann N Y Acad Sci 949:123-133

4. Slamon DJ, Romond EH, Perez EA (2006) Advances in adjuvant therapy for breast cancer. Clin Adv Hematol Oncol 4(Suppl 1): 4-9 (discussion suppl. 10: quiz $12 \mathrm{p}$ following suppl. 10)

5. Early Breast Cancer Trialists' Collaborative Group (EBCTCG) (2005) Effects of chemotherapy and hormonal therapy for early breast cancer on recurrence and 15-year survival: an overview of the randomised trials. Lancet 365(9472):1687-1717. doi:10.1016/ S0140-6736(05)66544-0

6. Sledge GW, Rugo HS, Burstein HJ (2006) The role of angiogenesis inhibition in the treatment of breast cancer. Clin Adv Hematol Oncol 4(Suppl 21):1-12

7. Slamon DJ, Leyland-Jones B, Shak S et al (2001) Use of chemotherapy plus a monoclonal antibody against HER2 for metastatic breast cancer that overexpresses HER2. N Engl J Med 344:783-792. doi:10.1056/NEJM200103153441101

8. Moy B, Kirkpatrick P, Kar S, Goss P (2007) Lapatinib. Nat Rev Drug Discov 6:431-432. doi:10.1038/nrd2332

9. Von Hoff DD, Layard MW, Basa P et al (1979) Risk factors for doxorubicin-induced congestive heart failure. Ann Intern Med 91:710-717

10. Von Hoff DD, Rozencweig M, Piccart M (1982) The cardiotoxicity of anticancer agents. Semin Oncol 9:23-33

11. Swain SM, Whaley FS, Ewer MS (2003) Congestive heart failure in patients treated with doxorubicin: a retrospective analysis of three trials. Cancer 97(11):2869-2879. doi:10.1002/cncr.11407

12. Batist G (2007) Cardiac safety of liposomal anthracyclines. Cardiovasc Toxicol 7:72-74. doi:10.1007/s12012-007-0014-4

13. Lorusso V, Manzione L, Silvestris N (2007) Role of liposomal anthracyclines in breast cancer. Ann Oncol 18(Suppl 6): 70-73. doi:10.1093/annonc/mdm229

14. Batist G, Barton J, Chaikin P et al (2002) Myocet (liposomeencapsulated doxorubicin citrate): a new approach in breast cancer therapy. Expert Opin Pharmacother 3:1739-1751. doi: 10.1517/14656566.3.12.1739

15. Batist G, Harris L, Azarnia N et al (2006) Improved anti-tumor response rate with decreased cardiotoxicity of non-pegylated liposomal doxorubicin compared with conventional doxorubicin in first-line treatment of metastatic breast cancer in patients who had received prior adjuvant doxorubicin: results of a retrospective analysis. Anticancer Drugs 17:587-595. doi:10.1097/00001813200606000-00014

16. Swenson CE, Bolcsak LE, Batist G et al (2003) Pharmacokinetics of doxorubicin administered i.v. as Myocet (TLC D-99; liposomeencapsulated doxorubicin citrate) compared with conventional doxorubicin when given in combination with cyclophosphamide in patients with metastatic breast cancer. Anticancer Drugs 14:239-246. doi:10.1097/00001813-200303000-00008

17. Harris L, Batist G, Belt R et al (2002) Liposome-encapsulated doxorubicin compared with conventional doxorubicin in a randomized multicenter trial as first-line therapy of metastatic breast carcinoma. Cancer 94:25-36. doi:10.1002/cncr.10201

18. Batist G, Ramakrishnan G, Rao CS et al (2001) Reduced cardiotoxicity and preserved antitumor efficacy of liposomeencapsulated doxorubicin and cyclophosphamide compared with conventional doxorubicin and cyclophosphamide in a randomized, multicenter trial of metastatic breast cancer. J Clin Oncol 19:1444-1454

19. Shapiro CL, Ervin T, Welles L et al (1999) Phase II trial of highdose liposome-encapsulated doxorubicin with granulocyte colony-stimulating factor in metastatic breast cancer. TLC D-99 study group. J Clin Oncol 17:1435-1441

20. Valero V, Buzdar AU, Theriault RL et al (1999) Phase II trial of liposome-encapsulated doxorubicin, cyclophosphamide, and fluorouracil as first-line therapy in patients with metastatic breast cancer. J Clin Oncol 17:1425-1434

21. Modi S, Seidman AD (2004) Single-agent gemcitabine in the treatment of advanced breast cancer. Clin Breast Cancer 4(Suppl 3):S101-S106. doi:10.3816/CBC.2004.s.002

22. Seidman AD (2001) The evolving role of gemcitabine in the management of breast cancer. Oncology 60:189-198. doi: $10.1159 / 000055318$

23. Modi S, Currie VE, Seidman AD et al (2005) A phase II trial of gemcitabine in patients with metastatic breast cancer previously treated with an anthracycline and taxane. Clin Breast Cancer 6:55-60. doi:10.3816/CBC.2005.n.009

24. Perez-Manga G, Lluch A, Alba E et al (2000) Gemcitabine in combination with doxorubicin in advanced breast cancer: final results of a phase II pharmacokinetic trial. J Clin Oncol 18: $2545-2552$

25. Therasse P, Arbuck SG, Eisenhauer EA, Wanders J, Kaplan RS, Rubinstein L, Verweij J, van Glabbeke M, van Oosterom AT, Christian MC, Gwyther SG (2000) New guidelines to evaluate the response to treatment in solid tumors. European Organization for Research and Treatment of Cancer, National Cancer Institute of the United States, National Cancer Institute of Canada. J Natl Cancer Inst 92(3):205-216. doi:10.1093/jnci/92.3.205

26. Kaplan E, Meier P (1959) Non-parametric estimation from incomplete observations. J Am Stat Assoc 53:457-481. doi: $10.2307 / 2281868$

27. Cox DR (1970) The analysis of binary data. Methuen, London

28. Rivera E, Valero V, Arun B et al (2003) Phase II study of pegylated liposomal doxorubicin in combination with gemcitabine in patients with metastatic breast cancer. J Clin Oncol 21:3249-3254. doi:10.1200/JCO.2003.03.111

29. Fabi A, Ferretti G, Papaldo P et al (2006) Pegylated liposomal doxorubicin in combination with gemcitabine: a phase II study in anthracycline-naive and anthracycline pretreated metastatic breast cancer patients. Cancer Chemother Pharmacol 57:615623. doi:10.1007/s00280-005-0116-2

30. Campone M, Fumoleau P, Viens P et al (2006) Gemcitabine and epirubicin in patients with metastatic breast cancer: a phase I/II study. Breast 15:601-609. doi:10.1016/j.breast.2005.11.010 